\title{
High temperature-high pressure thermal conductivities of ethylene and propane
}

\author{
Mahesh C. Aggarwal and George S. Springer \\ Department of Mechanical Engineering, The University of Michigan, Ann Arbor, Michigan 48109 \\ (Received 3 July 1978) \\ Thermal conductivities $\lambda$ of ethylene and propane were measured in the temperature and pressure ranges \\ $400-750 \mathrm{~K}$ and $0.1-2.65 \mathrm{MPa}$ (ethylene) and 400-725 $\mathrm{K}$ and 0.1 to $0.6 \mathrm{MPa}$ (propane). The data were \\ correlated by expressions of the form $\lambda=\lambda_{0}(T) \times \lambda_{p}(P)$, with $\lambda_{0}$ being a second order polynomial in \\ temperature and $\lambda_{p}$ a third (ethylene) or a fourth (propane) order polynomial in pressure. The results \\ obtained were compared with previous thermal conductivity measurements.
}

\section{INTRODUCTION}

In the previous paper, ${ }^{1}$ an apparatus was described for measuring thermal conductivities of gases at high temperatures and at high pressures. In this paper, experimental results are presented for ethylene and propane. In order to prevent the formation of multicellular convection, the temperatures and pressures were kept at values which resulted in Rayleigh numbers less than the critical Rayleigh number of $5 \times 10^{4}$ (see Ref. 1). Thus, the thermal conductivity values of ethylene were measured in the ranges 400 to $750 \mathrm{~K}$ and 0.1 to $2.65 \mathrm{MPa}$. The lowest temperature and pressure used for propane was also 400 $\mathrm{K}$ and $0.1 \mathrm{MPa}$. The highest temperature and pressure reached with propane was $725 \mathrm{~K}$ and $0.6 \mathrm{MPa}$. At high pressures, propane liquified at room temperature.

Laboratory grade test gases of purities $99.5 \%$ (ethylene) and $99 \%$ (propane) were used in the experiments.

\section{RESULTS}

The measured heat transfer values are listed in Tables I and II. The thermal conductivities of ethylene and propane were determined by substituting the polynomial

$$
\lambda=a+b T+c T^{2}
$$

into the Fourier equation [Eq. (10) in Ref. 1], and by integrating the resulting equation between $d / 2$ and $D / 2$. By neglecting the corrections for temperature drop across the column $\lambda^{\prime}$, temperature jump at the filament surface $\lambda^{\prime \prime}$, and thermal expansion of the filament $\lambda^{\prime \prime \prime}$, the integration gave

$\frac{Q \lambda}{2 \pi} \ln (D / d)=a\left(T_{f}-T_{b}\right)+\frac{b}{2}\left(T_{f}^{2}-T_{b}^{2}\right)+\frac{c}{3}\left(T_{f}^{3}-T_{b}^{3}\right)$.

At each pressure, the values of $Q_{\lambda}\left(\mathrm{W} \mathrm{m}^{-1}\right)$ and $T_{f}(\mathrm{~K}) \mathrm{giv}$ en in Tables I and II were used to fit a least squares curve through Eq. (2). With this procedure, the values of the constants $a, b$, and $c$ were determined at six pressures (Table III). Once $a, b$, and $c$ were determined, the values of $\lambda$ (Tables IV and V) and the values of $\lambda^{\prime}$, $\lambda^{\prime \prime}$, and $\lambda^{\prime \prime}$ were calculated. The total contributions of $\lambda^{\prime}, \lambda^{\prime \prime}$, and $\lambda^{\prime \prime \prime}$ to $\lambda$ were found to be always less than $0.2 \%$.

Similar to argon, ${ }^{1}$ it was found for both ethylene and propane that the thermal conductivity could be expressed as

$$
\lambda=\lambda(T, P)=\lambda_{T}(T) \cdot \lambda_{D}(P),
$$

where $\lambda_{T}\left(\mathrm{~W} \mathrm{~m}^{-1} \mathrm{~K}^{-1}\right)$ and $\lambda_{p}$ (dimensionless) are only functions of temperature and pressure, respectively. By taking $\lambda_{T}$ to be the thermal conductivity of the gas at $0.1 \mathrm{MPa}$ and by representing this value by $\lambda_{0}$, we have

$$
\lambda_{T}=\lambda_{0}=a_{0}+b_{0} T+c_{0} T^{2} \text {. }
$$

\begin{tabular}{|c|c|c|c|c|c|c|}
\hline $\begin{array}{l}P \\
(\mathrm{MPa})\end{array}$ & $\begin{array}{l}T_{f} \\
(\mathrm{~K})\end{array}$ & $\begin{array}{l}\bar{Q}_{m s} \\
(\mathrm{~W})\end{array}$ & $\begin{array}{l}\bar{Q}_{m L} \\
(W)\end{array}$ & $\begin{array}{l}\overline{Q_{m s}^{V}} \\
\text { (W) }\end{array}$ & $\begin{array}{l}\bar{Q}_{m L}^{V} \\
(W)\end{array}$ & $\begin{array}{l}Q_{x} \\
\left(W m^{-1}\right)\end{array}$ \\
\hline \multirow[t]{8}{*}{0.1} & 395.0 & 1.432 & 2.396 & 0.0263 & 0.0459 & 7.72 \\
\hline & 434.8 & 2.049 & 3.493 & 0.0371 & 0.0698 & 11.53 \\
\hline & 479.7 & 2.823 & 4.899 & 0.0516 & 0.1059 & 16.52 \\
\hline & 528.9 & 3.775 & 6.662 & 0.0715 & 0.1549 & 22.92 \\
\hline & 583.6 & 4.951 & 8.884 & 0.0963 & 0.2229 & 31.10 \\
\hline & 643.0 & 6.382 & 11.619 & 0.1306 & 0.3192 & 41.25 \\
\hline & 702.8 & 8.142 & 14.947 & 0.1786 & 0.4505 & 53.39 \\
\hline & 769.7 & 10.177 & 18.911 & 0.2356 & 0.6314 & 68.14 \\
\hline \multirow[t]{8}{*}{0.64} & 394.4 & 1.413 & 2.373 & 0.0247 & 0.0442 & 7.69 \\
\hline & 433.2 & 2.032 & 3.466 & 0.0359 & 0.0683 & 11.46 \\
\hline & 478.4 & 2.806 & 4.876 & 0.0501 & 0.1031 & 16.48 \\
\hline & 526.8 & 3.773 & 6.659 & 0.0693 & 0.1514 & 22.92 \\
\hline & 579.3 & 4.933 & 8.833 & 0.0949 & 0.2183 & 30.86 \\
\hline & 640.1 & 6.350 & 11.560 & 0.1278 & 0.3116 & 41.08 \\
\hline & 700.5 & 8.076 & 14.860 & 0.1712 & 0.4405 & 53.24 \\
\hline & 768.2 & 10.082 & 18.797 & 0.2263 & 0.6163 & 68.04 \\
\hline \multirow[t]{8}{*}{1.16} & 392.5 & 1.393 & 2.349 & 0.0220 & 0.0405 & 7.66 \\
\hline & 432.2 & 2.015 & 3.445 & 0.0344 & 0.0661 & 11.43 \\
\hline & 474.9 & 2.781 & 4.832 & 0.0482 & 0.0994 & 16.34 \\
\hline & 522.7 & 3.740 & 6.592 & 0.0680 & 0.1466 & 22.67 \\
\hline & 576.4 & 4.910 & 8.791 & 0.0927 & 0.2137 & 30.73 \\
\hline & 634.2 & 6.361 & 11.531 & 0.1276 & 0.3059 & 40.79 \\
\hline & 697.4 & 8.008 & 14.763 & 0.1656 & 0.4268 & 53.07 \\
\hline & 762.0 & 9.975 & 18.610 & 0.2183 & 0.5931 & 67.50 \\
\hline \multirow[t]{8}{*}{1.68} & 390.7 & 1.398 & 2.346 & 0.0222 & 0.0327 & 7.66 \\
\hline & 427.6 & 2.002 & 3.409 & 0.0336 & 0.0640 & 11.25 \\
\hline & 473.1 & 2.773 & 4.819 & 0.0467 & 0.0981 & 16.30 \\
\hline & 520.1 & 3.720 & 6.557 & 0.0662 & 0.1431 & 22.56 \\
\hline & 569.9 & 4.863 & 8.686 & 0.0904 & 0.2049 & 30.31 \\
\hline & 626.5 & 6.262 & 11.345 & 0.1222 & 0.2909 & 40.17 \\
\hline & 686.8 & 7.924 & 14.545 & 0.1612 & 0.4081 & 52.10 \\
\hline & 751.7 & 9.904 & 18.398 & 0.2144 & 0.5705 & 66.51 \\
\hline \multirow[t]{9}{*}{2.17} & 380.8 & 1.239 & 2.088 & 0.0229 & 0.0328 & 6.85 \\
\hline & 415.7 & 1.826 & 3.103 & 0.0296 & 0.0554 & 10.23 \\
\hline & 456.9 & 2.553 & 4.391 & 0.0424 & $0.084 b$ & 14.68 \\
\hline & 503.2 & 3,444 & 6.028 & 0.0600 & 0.1282 & 20.56 \\
\hline & 554.1 & 4.528 & 8.056 & 0.0807 & 0.1822 & 28.09 \\
\hline & 608.5 & 5.850 & 10.556 & 0.1105 & 0.2607 & 37.23 \\
\hline & 665.5 & 7.430 & 13.583 & 0.1467 & 0.3622 & 48.52 \\
\hline & 727.2 & 9.317 & 17,220 & 0.1938 & 0.5057 & 62.04 \\
\hline & 793.6 & 11.461 & 21.490 & 0.2478 & 0.6898 & 78.35 \\
\hline \multirow[t]{9}{*}{2.65} & 386.3 & 1.350 & 2.283 & 0.0191 & 0.0356 & 7,49 \\
\hline & 421.6 & 1.972 & 3.357 & 0.0304 & 0.0592 & 11.09 \\
\hline & 464.7 & 2.738 & 4.740 & 0.0448 & 0.0905 & 15.98 \\
\hline & 510.1 & 3.682 & 6.460 & 0.0633 & 0.1261 & 22.19 \\
\hline & 558.7 & 4.807 & 8.541 & 0.0880 & 0.1932 & 29.65 \\
\hline & 614.3 & 6.155 & 11.114 & 0.1147 & 0.2711 & 39.25 \\
\hline & 674.6 & 7.820 & 14.304 & 0.1548 & 0.3837 & 51.12 \\
\hline & 734.9 & 9.698 & 17,978 & 0.1974 & 0.5216 & 65.02 \\
\hline & 803.2 & 11.99 & 22.527 & 0.2562 & 0.7187 & 82.34 \\
\hline
\end{tabular}

TABLE I. Tabulation of the ethylene data. Symbols are defined in Ref. $1 ; L_{S}=34.120 \mathrm{~cm}, L_{L}=46.356 \mathrm{~cm}$. 
TABLE II. Tabulation of the propane data. Symbols are defined in Ref. (1); $L_{S}=34.230 \mathrm{~cm}, L_{L}=46.356 \mathrm{~cm}$.

\begin{tabular}{|c|c|c|c|c|c|c|}
\hline $\begin{array}{l}\bar{P} \\
(\mathrm{MPa})\end{array}$ & $\begin{array}{l}T_{f} \\
\text { (K) }\end{array}$ & $\begin{array}{l}\bar{Q}_{m s} \\
(W)\end{array}$ & $\begin{array}{l}\bar{Q}_{m L} \\
(W)\end{array}$ & $\begin{array}{l}\bar{Q}_{m s}^{V} \\
(W)\end{array}$ & $\begin{array}{l}\bar{Q}_{m L}^{V} \\
(W)\end{array}$ & $\begin{array}{l}Q_{\lambda} \\
\left(W m^{-1}\right)\end{array}$ \\
\hline \multirow[t]{8}{*}{0.1} & 372.9 & 1.057 & 1.697 & 0.0202 & 0.0279 & 5.21 \\
\hline & 410.4 & 1.586 & 2.594 & 0.0303 & 0.0476 & 8.17 \\
\hline & 452.7 & 2.262 & 3.764 & 0.0437 & 0.0760 & 12.12 \\
\hline & 499.9 & 3.159 & 5.317 & 0.0663 & 0.1199 & 17.35 \\
\hline & 549.7 & 4.281 & 7.284 & 0.0966 & 0.1824 & 24.06 \\
\hline & 605.0 & 5.611 & 9.671 & 0.1331 & 0.2705 & 32.35 \\
\hline & 667.0 & 7.252 & 12.672 & 0.1840 & 0.3976 & 42.94 \\
\hline & 725.3 & 9.227 & 16.213 & 0.2530 & 0.5603 & 55.08 \\
\hline \multirow[t]{8}{*}{0.2} & 372.2 & 1.038 & 1.667 & 0.0202 & 0.0279 & 5.12 \\
\hline & 409.3 & 1.574 & 2.574 & 0.0303 & 0.0460 & 8.11 \\
\hline & 451.6 & 2.243 & 3.732 & 0.0425 & 0.0745 & 12.02 \\
\hline & 499.3 & 3.146 & 5.295 & 0.0663 & 0.1107 & 17.36 \\
\hline & 549.0 & 4.237 & 7.214 & 0.0945 & 0.1797 & 23.85 \\
\hline & 604.6 & 5.621 & 9.678 & 0.1348 & 0.2721 & 32.33 \\
\hline & 662.7 & 7.244 & 12.611 & 0.1841 & 0.3911 & 42.55 \\
\hline & 729.8 & 9.308 & 16.377 & 0.2560 & 0.5714 & 55.70 \\
\hline \multirow[t]{8}{*}{0.3} & 372.2 & 1.039 & 1.668 & 0.0207 & 0.0279 & 5.12 \\
\hline & 409.5 & 1.574 & 2.572 & 0.0304 & 0.0471 & 8.09 \\
\hline & 451.0 & 2.280 & 3.775 & 0.0461 & 0.0770 & 12.07 \\
\hline & 496.8 & 3.128 & 5.258 & 0.0652 & 0.1186 & 17.12 \\
\hline & 549.7 & 4.232 & 7.214 & 0.0944 & 0.1797 & 23.89 \\
\hline & 605.8 & 5.577 & 9.622 & 0.1330 & 0.2691 & 32.24 \\
\hline & 662.5 & 7.235 & 12.593 & 0.1842 & 0.3912 & 42.48 \\
\hline & 728.4 & 9.186 & 16.203 & 0.2487 & 0.5600 & 55.30 \\
\hline \multirow[t]{8}{*}{0.4} & 371.5 & 1.037 & 1.664 & 0.0202 & 0.0275 & 5.11 \\
\hline & $\$ 10.1$ & 1.580 & 2.583 & 0.0303 & $0.0 \$ 71$ & 8.13 \\
\hline & 453.3 & 2.282 & 3.791 & 0.0451 & 0.0769 & 12.19 \\
\hline & 497.2 & 3.115 & 5.245 & 0.0640 & 0.1159 & $17.1 t$ \\
\hline & 548.5 & 4. 247 & 7.228 & 0.0951 & 0.1808 & 23.88 \\
\hline & 605.5 & 5.596 & 9.653 & 0.1330 & 0.2704 & 32.33 \\
\hline & 663.9 & 7.215 & 12.588 & 0.1818 & 0.3890 & 42.60 \\
\hline & 727.8 & 9.205 & 16.225 & 0.2488 & 0.5599 & 55.32 \\
\hline \multirow[t]{8}{*}{0.5} & 371.5 & 1.037 & 1.663 & 0.0199 & 0.0275 & 5.11 \\
\hline & 408.1 & 1.564 & 2.555 & 0.0296 & 0.0460 & 8.04 \\
\hline & 450.7 & 2.251 & 3.731 & 0.0443 & 0.0754 & 11.97 \\
\hline & 497.6 & 3.123 & 5.256 & 0.0651 & 0,1169 & 17.16 \\
\hline & 549.0 & 4.218 & 7.194 & 0.0930 & 0.1783 & 23.84 \\
\hline & 603.1 & 5.559 & 9. 593 & 0.1302 & 0,2638 & 32.17 \\
\hline & 662.5 & 7.204 & 12.557 & 0.1818 & 0.3869 & 42.45 \\
\hline & 724.2 & 9.140 & 16.094 & 0.2460 & 0.5493 & 54.85 \\
\hline \multirow[t]{8}{*}{0.6} & 372.6 & 1.054 & 1.695 & 0.0197 & 0.0275 & 5.22 \\
\hline & 409.9 & 1.594 & 2.611 & 0.0296 & 0,0465 & 8.25 \\
\hline & 451.4 & 2.266 & 3.773 & 0.0424 & 0.0738 & 12.17 \\
\hline & +98.0 & 3,124 & 5,283 & 0.0611 & 0.1145 & 17.36 \\
\hline & 548.1 & 4.224 & 7.219 & 0.0900 & 0,1743 & 24.01 \\
\hline & 601.2 & 5.554 & 9.596 & 0.1272 & 0.2585 & 32.25 \\
\hline & 663.1 & 7.158 & 12.545 & 0.1718 & 0.3777 & 42.73 \\
\hline & 726.8 & 9.211 & 16.293 & 0.2381 & 0.5440 & 55.88 \\
\hline
\end{tabular}

\section{A. Ethylene}

For ethylene, the thermal conductivity as a function of temperature and pressure was written as

$$
\begin{aligned}
\lambda= & \left(a_{0}+b_{0} T+c_{0} T^{2}\right) \\
& \times\left[1+A\left(\frac{P-P_{0}}{P_{0}}\right)+B\left(\frac{P-P_{0}}{P_{0}}\right)^{2}+C\left(\frac{P-P_{0}}{P_{0}}\right)^{3}\right],
\end{aligned}
$$

where $P_{B}=0.1 \mathrm{MPa}$. The constants $A, B$, and $C$ were determined by employing a least squares fit through Eq. (5) using the experimental values of $\lambda$ and $\lambda_{0}$ [Eqs. (1) and (4)], and the corresponding values of pressure $P$. The foregoing procedure yielded the values of the constants $A, B$, and $C$ given in Table III.

With these constants, Eq. (5) described the data with a standard deviation of $1 \times 10^{-5}$. Third, fourth, and fifth order polynomials in temperature and fourth and fifth order polynomials in pressure were also fitted to the data. These polynomials did not improve the correlation significantly.
TABLE III. The constants $a, b, c$, and $A, B, C, D$. The units of $a, b, c$ are such as to give $\lambda$ in $\mathrm{W} \mathrm{m}^{-1} \mathrm{~K}^{-1}$ when $T$ is in $\mathrm{K}$. $A$,

\begin{tabular}{|c|c|c|c|}
\hline Pressure (MPa) & $a \times 10^{1}$ & $b \times 10^{3}$ & $c \times 10^{7}$ \\
\hline & \multicolumn{3}{|c|}{ Ethylene } \\
\hline 0.1 & -0.1768 & 0.1189 & 0.2328 \\
\hline 0.64 & -0.1749 & 0.1183 & 0.2469 \\
\hline 1.16 & -0.1791 & 0.1206 & 0.2440 \\
\hline 1.68 & -0.1862 & 0.1245 & 0.2312 \\
\hline 2.17 & -0.1874 & 0.1258 & 0.2515 \\
\hline \multirow[t]{2}{*}{2.65} & -0.1897 & 0.1279 & 0.2600 \\
\hline & \multicolumn{3}{|c|}{ Propane } \\
\hline 0.1 & -0.1595 & 0.0989 & 0.4409 \\
\hline 0.2 & -0.1595 & 0.0989 & 0.4409 \\
\hline 0.3 & -0.1639 & 0.1008 & 0.4214 \\
\hline 0.4 & -0.1623 & 0.0999 & 9.4344 \\
\hline 0.5 & -0.1640 & 0.1010 & 0.4264 \\
\hline 0.6 & -0.1635 & 0.1009 & 0.4410 \\
\hline Ethylene & & \multicolumn{2}{|c|}{ Propane } \\
\hline $0.1185 \times 10^{-3}$ & & \multicolumn{2}{|c|}{$0.1458 \times 10^{-3}$} \\
\hline $0.1856 \times 10^{-3}$ & & \multicolumn{2}{|c|}{$0.1205 \times 10^{-3}$} \\
\hline$-0.2493 \times 10^{-5}$ & & \multicolumn{2}{|c|}{$-0.1846 \times 10^{-3}$} \\
\hline$D$ & & \multicolumn{2}{|c|}{$0.5222 \times 10^{-4}$} \\
\hline
\end{tabular}
$B, C$, and $D$ are dimensionless.

A comparison between the heat conduction calculated using $\lambda$ given by Eq. (5) and the heat conduction measured yields a maximum difference of $0.6 \%$ (Fig. 1). Using the analysis given in Ref. 1 , the most probable random error in the data was estimated to range from $1.51 \%-1.78 \%$. The maximum systematic error was estimated to be $0.95 \%$.

The only available information on the thermal conductivity of ethylene is that reported by Vargaftik ${ }^{2}$ and Misic and Thodos..$^{3}$ Vargaftik's tables give values of $\lambda$ up to pressures of $150 \mathrm{MPa}$ in the temperature range of 300 to $500 \mathrm{~K}$. Therefore, a direct comparison between the present results and those given by Vargaftik could be made only at $0.1 \mathrm{MPa}$ and at temperatures between 400 and $500 \mathrm{~K}$. The results are presented in Fig. 2. The values given by Vargaftik seem to be $2 \%$ to $6 \%$ higher than those obtained in the present experiments.

Misic and Thodos developed the following expression for the thermal conductivities of hydrocarbons:

TABLE IV. Thermal conductivity of ethylene calculated using Eq. (1) and the constants $a, b$, and $c$ given in Table III.

\begin{tabular}{lllllll}
\hline \hline (MPa) & 0.1 & 0.64 & 1.16 & 1.68 & 2.17 & 2.65 \\
\hline$T(\mathrm{~K})$ & & \multicolumn{5}{c}{$\lambda \times 10^{3}\left(\mathrm{~W} \mathrm{~m}^{-1} \mathrm{~K}^{-1}\right)$} \\
\hline 400 & $\mathbf{3 3 . 6 0}$ & $\mathbf{3 3 . 7 8}$ & $\mathbf{3 4 . 2 1}$ & $\mathbf{3 4 . 9 0}$ & $\mathbf{3 5 . 5 8}$ & 36.36 \\
450 & 40.54 & 40.75 & 41.28 & 42.11 & 42.94 & 43.86 \\
500 & 47.59 & 47.82 & 48.47 & 49.43 & 50.42 & 51.50 \\
550 & 54.75 & 55.04 & 55.78 & 56.87 & 58.03 & 59.26 \\
600 & 62.04 & 62.37 & 63.21 & 64.43 & 65.77 & 67.15 \\
650 & 69.43 & 69.83 & 70.76 & 72.10 & 73.62 & 75.17 \\
700 & 76.95 & 77.41 & 78.43 & 79.89 & 81.61 & 83.32 \\
750 & 84.58 & 85.11 & 86.23 & 87.79 & 89.72 & $\mathbf{9 1 . 6 1}$ \\
\hline \hline
\end{tabular}


TABLE V. Thermal conductivity of propane calculated using Eq. (1) and the constants $a, b$, and $c$ given in Table III.

\begin{tabular}{lcccccc}
\hline \hline$P(\mathrm{MPa})$ & 0.1 & 0.2 & 0.3 & 0.4 & 0.5 & 0.6 \\
\hline$T(\mathrm{~K})$ & \multicolumn{5}{c}{$\lambda \times 10^{3}\left(\mathrm{~W} \mathrm{~m}^{-1} \mathrm{~K}^{-1}\right)$} \\
\hline 400 & 30.67 & 30.67 & 30.68 & 30.68 & 30.81 & 31.07 \\
450 & 37.49 & 37.49 & 37.52 & 37.52 & 37.67 & 37.99 \\
500 & 44.53 & 44.53 & 44.56 & 44.58 & 44.74 & 45.13 \\
550 & 51.79 & 51.79 & 51.81 & 51.85 & 52.03 & 52.49 \\
600 & 59.27 & 59.27 & 59.28 & 59.34 & 59.53 & 60.07 \\
650 & 66.98 & 66.98 & 66.95 & 67.05 & 67.24 & 67.87 \\
700 & 74.90 & 74.90 & 74.84 & 74.98 & 75.17 & 75.90 \\
725 & 78.94 & 78.94 & 78.86 & 79.03 & 79.21 & 79.99 \\
\hline \hline
\end{tabular}

$$
\lambda(T)=\frac{\bar{c}_{p} \times 10^{-4}\left[14.52\left(T / T_{c}\right)-5.14\right]^{2 / 3}}{M^{1 / 2}\left(T_{c}\right)^{1 / 6}}\left(\frac{10 P_{c}}{1.0133}\right)^{2 / 3},
$$

where $\bar{c}_{p}$ is in $\mathrm{kJ} \mathrm{kmole}{ }^{-1} \mathrm{~K}^{-1}, M$ is the molecular weight of the gas, and $T_{c}$ and $P_{c}$ are the critical temperature (K) and pressure $(\mathrm{MPa})$, respectively. In principle, this expression [Eq. (6)] is applicable up to $0.5 \mathrm{MPa}$. In practice, it is difficult to use it beyond $0.1 \mathrm{MPa}$ because the literature does not report accurate specific heat values at higher pressures. Therefore, comparison was made between the present values of $\lambda[\mathrm{Eq}$. (5)] and those calculated using Eq. (6) at $0.1 \mathrm{MPa}$ only. For this comparison, the values of $\bar{c}_{p}$ were taken from Ref. 4 and the values of $M, T_{c}$, and $P_{c}$ from Ref. 2. The results given in Fig. 2 show a maximum difference of $0.35 \%$ between the present values of $\lambda$ and those obtained by the MisicThodos expression.

\section{B. Propane}

The thermal conductivity of propane as a function of temperature and pressure was written as

$$
\begin{aligned}
\lambda= & \left(a_{0}+b_{0} T+c_{0} T^{2}\right)\left[1+A\left(\frac{P-P_{0}}{P_{0}}\right)+B\left(\frac{P-P_{0}}{P_{0}}\right)^{2}\right. \\
& \left.+C\left(\frac{P-P_{0}}{P_{0}}\right)^{3}+D\left(\frac{P-P_{0}}{P_{0}}\right)^{4}\right] .
\end{aligned}
$$

The constants $A, B, C$, and $D$ were again determined

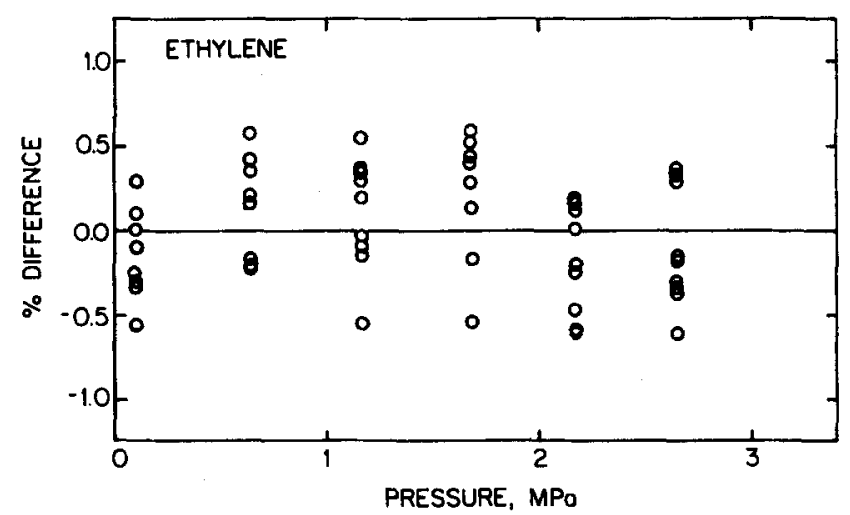

FIG. 1. Percent differences between the measured heat conduction and the heat conduction calculated using the thermal conductivity values given by Eq. (5). The points shown are for temperatures $400-750 \mathrm{~K}$.

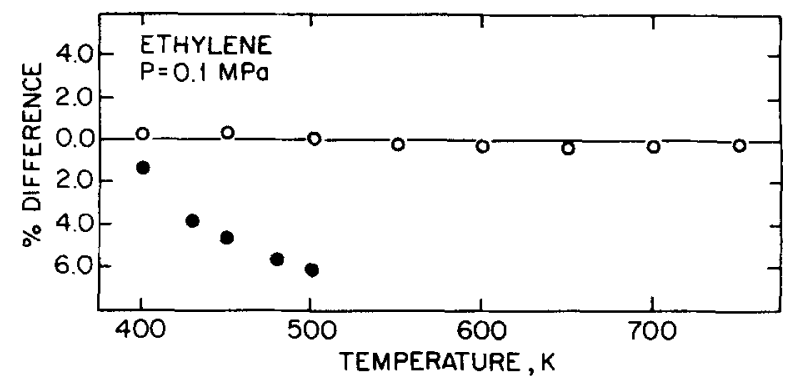

FIG. 2. Percent differences between the thermal conductivity values obtained in the present investigation [Eq. (5)] and the values reported by previous investigators. OMisic and Thodos ${ }^{3}$ $(400-750 \mathrm{~K})$; - Vargaftik ${ }^{2}(400-500 \mathrm{~K})$.

by using a least squares fit through Eq. (7) by employing the experimental values of $\lambda$ and $\lambda_{0}$ [Eqs. (1) and (4)] and the corresponding values of pressure $P\left(P_{0}=0.1 \mathrm{MPa}\right)$. The constants $A, B, C$, and $D$ obtained by this procedure are given in Table III. With the constants given in Table III, Eq. (7) described the data with a standard deviation of $1 \times 10^{-5}$. Higher-order polynomials in both temperature and pressure (up to fifth order) did not seem to improve the correlation.

A comparison between the values calculated using $\lambda$ given by Eq. (7) and values of heat conduction measured is shown in Fig. 3. The maximum difference between the calculated and measured values of heat conduction was $0.6 \%$. Using the analysis given in Ref. 1 , the most probable random error in the data was estimated to range from $1.51 \%-1.78 \%$. The maximum systematic error was estimated to be $0.93 \%$.

All values of the thermal conductivity of propane reported in the literature are for a pressure of $0.1 \mathrm{MPa}$. At this pressure, Ehya, Faubert, and Springer ${ }^{5}$ made measurements of the thermal conductivity of propane in the temperature range of 300 to $1000 \mathrm{~K}$. Vargaftik ${ }^{2}$ reported the values of thermal conductivity for propane between 250 and $825 \mathrm{~K}$. Measurements were performed at $478 \mathrm{~K}$ by Mann and Dickens. ${ }^{6}$ Vines and Bennett ${ }^{7}$ measured thermal conductivity values at 399 and $422 \mathrm{~K}$. Values were reported by Leng and $\mathrm{Comings}^{8}$ at $413 \mathrm{~K}$

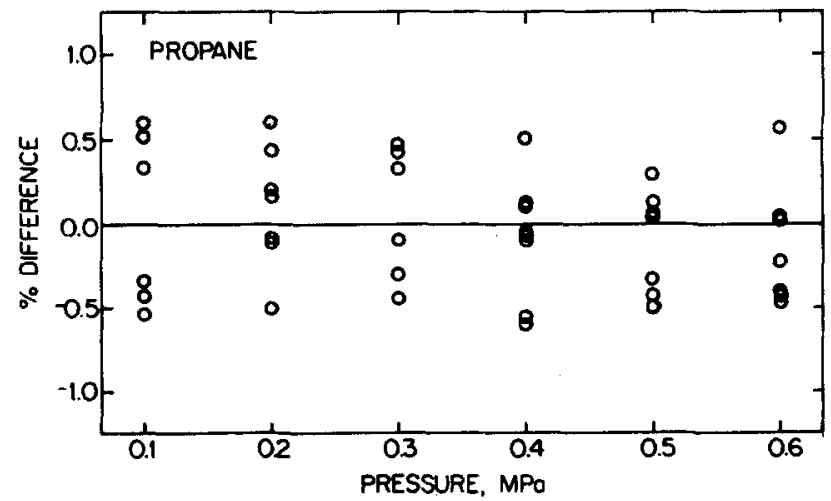

FIG. 3. Percent differences between the measured heat conduction and the heat conduction calculated using the thermal conductivity values given by Eq. (7). The points shown are for temperatures $400-725 \mathrm{~K}$. 


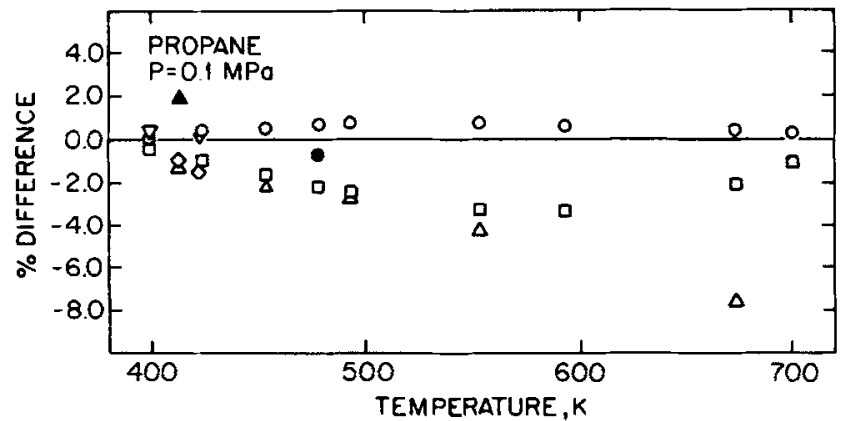

FIG. 4. Percent differences between the thermal conductivity values obtained in the present investigation [Eq. (7)] and the values reported by previous investigators. O Ehya, Faubert, and Springer ${ }^{5}(399-700 \mathrm{~K})$; $\square$ Misic and Thodos $^{3}$ (399-700 K); $\triangle$ Vargaftik $^{2}(413-673 \mathrm{~K}) ; \nabla$ Smith, Durbin, and Kobayashi ${ }^{9}$ $(398$ and $423 \mathrm{~K})$; $\diamond$ Vines and Bennett ${ }^{7}(413$ and $422 \mathrm{~K})$; - Mann and Dickens ${ }^{6}(478 \mathrm{~K}) ; .4$ Leng and Comings ${ }^{8}(413 \mathrm{~K})$.

while Smith, Durbin, and Kobayashi ${ }^{9}$ measured thermal conductivity values at 398 and $423 \mathrm{~K}$.

Figure 4 compares the present results given by Eq. (7) and those reported previously. Below $450 \mathrm{~K}$, the present data agree with those reported previously to within $2 \%$. In the temperature range of 400 to $700 \mathrm{~K}$, the present results agree with those given by Ehya, Faubert, and Springer to within $0.5 \%$. The Misic-Thodos expression [Eq. (6)] yields thermal conductivity values which are $1 \%-3 \%$ higher than those given by present experiments. The values given by Vargaftik in the temperature range of $413-673 \mathrm{~K}$ seem to be $1 \%-7.5 \%$ higher than those given by present experiments. Convection effects may account for the higher thermal conductivity values reported previously, $2,3,6,7$

\section{ACKNOWLEDGMENT}

This work was supported by the National Science Foundation.

${ }^{1}$ M. C. Aggarwal and G. S. Springer, J. Chem. Phys. 68, 3939 (1978), preceding paper.

${ }^{2}$ N. B. Vargaftik, Tables on the Thermophysical Properties of Liquids and Gases (Hemisphere Publishing Corporation, Washington-London, 1975), 2nd ed.

${ }^{3}$ D. Misic and G. Thodos, J. A. I. Ch.E. 7, 264 (1961).

${ }^{4}$ Y. S. Touloukian and T. Makita, Specific Heat, Nonmetallic Liquids and Gases, Vol, 6 in The TPRC Data Series, Thermophysical Properties of Matter (Plenum Press, New York, 1970).

${ }^{5}$ H. Ehya, F. M. Faubert, and G. S. Springer, Trans. ASME, J. Heat Transfer 94, 262 (1972).

${ }^{6}$ W. B. Mann and B. G. Dickens, Proc. Royal Society, London, Series A, 134, 77 (1932).

${ }^{7}$ R. G. Vines and L. A. Bennett, J. Chem. Phys. 22, 360 (1954).

${ }^{8}$ D. E. Leng and E. W. Comings, Ind. Eng. Chem. 49, 2042 (1957).

${ }^{9}$ W. J, S. Smith, L, D. Durbin, and R. Kobayashi, J. Chem. Eng. Data 5, 316 (1960). 